\title{
Growth and characterization of new borate-based crystal fibers by the micro-pulling down technique
}

\author{
M. Cochez ${ }^{1,2}$, F. Assi ${ }^{1,2}$, N. Kozhaya ${ }^{1,2}$, M. Ferriol ${ }^{1,2}$, M. Aillerie ${ }^{1,2}$, and G. Maxwell ${ }^{3}$ \\ ${ }^{1}$ Université de Lorraine, Laboratoire Matériaux Optiques, Photonique et Systèmes, E.A. 4423, Metz, France \\ ${ }^{2}$ Supélec, Laboratoire Matériaux Optiques, Photonique et Systèmes, E.A. 4423, Metz, France \\ ${ }^{3}$ Shasta Crystals Inc., Anderson, California, U.S.A.
}

Compact all solid-state lasers emitting in the blue and ultraviolet range are more and more required for numerous applications such as data storage, materials processing, photolithography, micromachining, sensors for the detection of gaseous pollutants, in biology or medicine. In this frame, single crystals allowing the generation of a blue/UV radiation by frequency conversion of an infrared one are promising materials. Crystals of the borate family are good candidates such as the compounds $\mathrm{Bi}_{2} \mathrm{ZnB}_{2} \mathrm{O}_{7}$ (BZBO) and $\mathrm{LaBGeO}_{5}$ (LBG) chemically stable and not hygroscopic. Bulk single crystals were very recently grown for the first time by the Czochralski and Kyropoulos techniques for BZBO [1-5] and by the Czochralski technique for LBG [6].

On the other hand, a big interest has arised for fiber crystal growth techniques such as the micro-pulling down ( $\mu$-PD) due to its unequalled specifications: high axial temperature gradients allowing high pulling rates, high length/diameter aspect ratio favorable to light propagation, high crystal quality,...These features allow to use the $\mu-P D$ set up in various ways such as growth of congruently melting compounds, growth of solid solution homogeneous crystals and solution/flux growth of incongruently melting compounds.

The purpose of this talk is to present our current results on the synthesis, growth and characterization of single crystal fibers of these two materials by the micro-pulling down technique.

\section{References}

1. N. Li, P. Fu, Y. Wu, J. Zhang, J. Cryst. Growth 311 3476 (2009)

2. F. Li, S. Pan, X. Hou, J. Yao, Cryst. Growth Des. 9 4091 (2009)

3. F. Li, X. Hou, S. Pan and X. Wang, Chem. Mater. 21 $2846(2009)$
4. F. Li, S. Pan, X. Hou, Z. Zhou, J. Cryst. Growth 3122383 (2010)

5. F. Li, S. Pan, J. Cryst. Growth 318629 (2011)

6. S. Miyazawa, S. Ichikawa, Y. Liu, S. Ji, T. Matsuoka, H. Nakae, Phys. Status Solidi A 2081195 (2011) 